“(C) 2018 IEEE. Personal use of this material is permitted. Permission from IEEE must be obtained for all other uses, in any current or future media, including reprinting/republishing this material for advertising or promotional purposes, creating new collective works, for resale or redistribution to servers or lists, or reuse of any copyrighted component of this work in other works." 


\title{
Comparative Study of Linear Superconductivity Machine with Different Stator and Winding Configurations
}

\author{
Shaopeng Wang, Youhua Wang, Chengcheng Liu, Gang Lei, \\ Jianguo Zhu, Senior Member, IEEE, and Youguang Guo, Senior Member, IEEE
}

\begin{abstract}
Compared with rotary electrical machine in linear drive applications, linear machine without rotary-linear motion conversion equipment can have higher force density and efficiency. Linear superconductivity machine (LSM) consists of high performance superconducting magnet instead of permanent magnet can offer very high force density and efficiency compared with other linear machines, such as linear induction machine, linear permanent magnet machine and so on. In this paper, LSM with different stators and winding configurations are investigated, specifically LSMs with concentrated winding or distributed winding and unilateral side stator or bilateral side stator. The electromagnetic parameters and performance of these LSMs are calculated and compared by using the finite element method (FEM), then the main difference of various design methods in LSM have been concluded.
\end{abstract}

Index Terms - linear superconductivity machine (LSM), concentrated winding, distributed winding, finite element method (FEM)

\section{INTRODUCTION}

C ompared with using traditional rotary machine, the linear drive systems can have high output force density, high efficiency, good mechanical robustness if the linear electrical machine is adopted, as there is no rotary-linear conversion mechanical device is required [1]-[5]. In the past decades, various kinds of linear machines had been proposed, including the linear induction machine, linear permanent magnet machine, linear reluctance machine and etc. [6]. Among these machines, the linear permanent magnet machine has shown the highest force density and efficiency, due to the adoption of high co-energy permanent magnet [7]. Currently, the high temperature superconductivity (HTS) has undergone a great step progress and it can be used in electromagnetic device which including the linear electrical machines and energy sys-

Manuscript receipt on 31 July 2018. (Corresponding author: Chengcheng Liu.)

Shaopeng Wang, chengcheng Liu and Youhua Wang are with State Key Laboratory of Reliability and Intelligence of Electrical Equipment, and Key Laboratory of Electromagnetic Field and Electrical Apparatus Reliability of Hebei Province, ( School of Electrical Engineering, Hebei University of Technology), Hongqiao District, TianJin, 300130, China (email:522396000@qq.com, 2016020@hebut.edu.cn, $\quad$ and wangyi@hebut.edu.cn )

Gang Lei, and Youguang Guo are with School of Electrical and Data Engineering, University of Technology Sydney (email: gang.lei@uts.eud.au , youguang.guo@uts.edu.au )

Jianguo Zhu is with School of Electrical and Information Engineering, University of Sydney (email: jianguo.zhu@uts.deu.au )

Digital Object Identifier will be inserted here upon acceptance. tem and etc. [8]. With adoption of HTS bulks, the linear superconductivity machine (LSM) can have very high force density and efficiency, if compared with the linear permanent magnet machine [9]-[11]. Recently, for the transportation application, a linear superconductivity machine (LSM) with HTS bulks had been proposed and verified [12]-[14].

Then LSM can have different characteristic when different topologies are applied. In this paper, the LSM with different stators and winding configurations, specifically the LSM with concentrated winding or distributed winding, and LSM with unilateral stator or bilateral stator are analyzed and compared, based on the finite element method (FEM). The electromagnetic parameters of the LSM with concentrated winding and unilateral mover can be verified by the experiment results in [15][16]. After the comparison, some profound conclusions can be drawn.

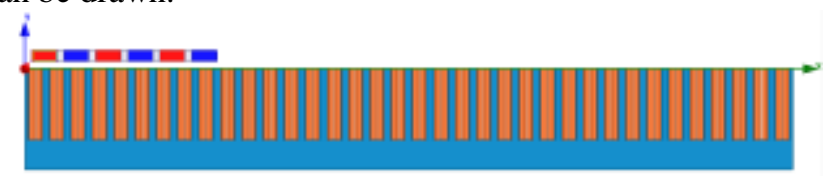

(a) Unilateral flat-plate LSM, LSM A

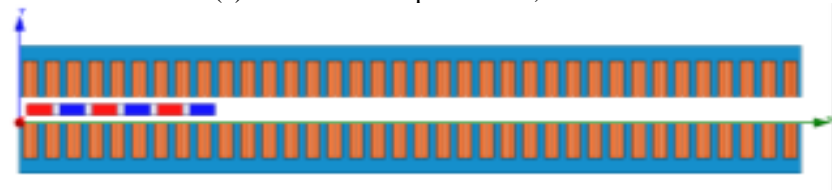

(b) Bilateral flat-plate LSM, LSM B

Fig. 1. Two LSMs with concentrated winding configuration

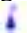

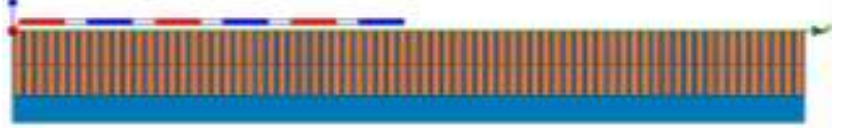

(a) Unilateral flat-plate LSM, LSM C

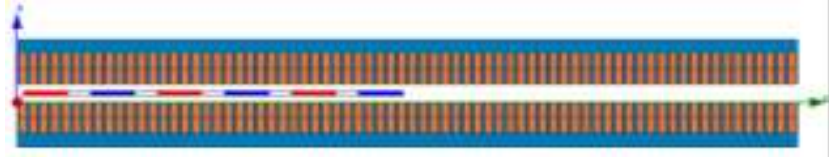

(b) Bilateral flat-plate LSM, LSM D

Fig. 2. Two LSMs with distributed winding configuration

\section{TOPOLOGIES AND WORKING PRINCIPLE OF SUPERCONDUCTIVITY LINEAR MACHINES}

The topologies of LSM with different stators and winding configurations are illustrated in Fig. 1 and Fig. 2. As shown, the LSM is designed with long primary stator and short secondary mover. In these figures, all complete secondary movers are shown. However, for the primary stator only part of them 
are shown. The primary stator is designed by using silicon steels and the secondary mover is designed by using HTS bulks. The stator length is considered to be infinite long and the number of HTS bulks is equal to 6 , thus the number of pole pairs of LSM is 3. The HTS bulk is made by the YBCO, and it can work under the temperature of $77 \mathrm{~K}$, its captured highest flux density is about $3.5 \mathrm{~T}$. Compared with the traditional linear PM machine, LSM has the advantages of high force density and efficiency. However, due to the limit of experiment condition, we just used the $0.5 \mathrm{~T}$ to represent its captured flux density in this paper. For the HTS bulks in the secondary mover, they are magnetized along y-direction and the adjacent HTS bulks are magnetized along the opposite directions. For different motor topologies, different sizes of HTS bulks are adopted. Especially in the LSM C and D, in order to achieve the number of slot per phase per pole equals 3 , the length of the HTS bulks are stretched thus the active length of these machines are different. For fair comparison, the volume of HTS bulks in all these four linear machines are kept the same. In the LSM with HTS bulks, a refrigeration system is essential. Conventional cooling methods include liquid cooling, and in short-range reciprocating motion, the Stirling engine is used to simplify the cooling system. YBCO coil magnets can be cooled to a temperature of $20 \mathrm{~K}$ by helium conduction cooling. [17][18]

TABLE I MAIN PARAMETERS OF THESE LSMS

\begin{tabular}{|c|c|c|c|c|}
\hline Items & LSM A & LSM C & LSM B & LSM D \\
\hline Stator type & \multicolumn{2}{|c|}{ Single } & \multicolumn{2}{|c|}{ Double } \\
\hline Winding type & Concentrated & Distributed & Concentrated & Distributed \\
\hline $\begin{array}{l}\text { Stator pole } \\
\text { pitch }(\mathrm{mm})\end{array}$ & 30 & 22 & 30 & 22 \\
\hline $\begin{array}{l}\text { Stator tooth } \\
\text { width }(\mathrm{mm})\end{array}$ & 10 & 10 & 10 & 10 \\
\hline $\begin{array}{l}\text { Stator slot } \\
\text { width }(\mathrm{mm})\end{array}$ & 20 & 12 & 20 & 12 \\
\hline $\begin{array}{l}\text { Stator tooth } \\
\text { high }(\mathrm{mm})\end{array}$ & 99 & 99 & 49.5 & 49.5 \\
\hline $\begin{array}{l}\text { Stator yoke } \\
\text { high }(\mathrm{mm})\end{array}$ & 41 & 41 & 20.5 & 20.5 \\
\hline $\begin{array}{l}\text { Number of super- } \\
\text { conductivity } \\
\text { blocks }\end{array}$ & \multicolumn{4}{|c|}{6} \\
\hline $\begin{array}{l}\text { Superconductivity } \\
\text { block high }(\mathrm{mm})\end{array}$ & 15 & $525 / 97$ & 15 & $525 / 97$ \\
\hline $\begin{array}{l}\text { Superconductivity } \\
\text { block width(mm) }\end{array}$ & 35 & 97 & 35 & 97 \\
\hline $\begin{array}{l}\text { Air gap length be- } \\
\text { tween stator and } \\
\text { mover }(\mathrm{mm})\end{array}$ & 10.5 & 10.5 & 10.5 & 10.5 \\
\hline $\begin{array}{l}\text { Air gap length be- } \\
\text { tween HTS } \\
\text { bulks(mm) }\end{array}$ & 10 & 35 & 10 & 35 \\
\hline Winding Turn & 200 & 160 & 100 & 80 \\
\hline
\end{tabular}

As shown in Fig. 1, LSM is designed with the configuration of 9 stator slots and 6 poles number. The main difference between LSM A and LSM B is that the LSM A is designed with one primary stator and one secondary mover while the LSM B is designed with one secondary mover in between of two primary stators. As shown in Fig. 2 the LSM C and LSM D both has the stator slot number of 36 and pole number of 6 . The main difference between LSM C and LSM D is that LSM D has two primary stators and one secondary mover. From the perspective of stator structure, the adoption of unilateral stator

structure will make the mover with normal force, this kind of force is required for some applications. However, only the thrust force along the motion direction is considered in this paper. As shown, LSM A and LSM B are designed with concentrated windings and LSM C and LSM D are designed with distributed windings. The main parameters of the motor are tabulated in Table. 1.

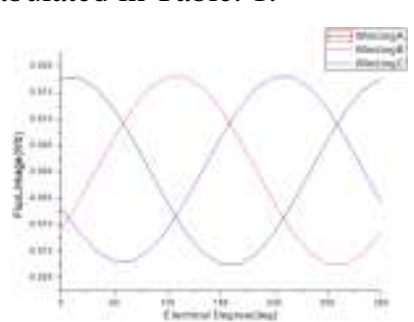

(a) Unilateral flat-plate LSM

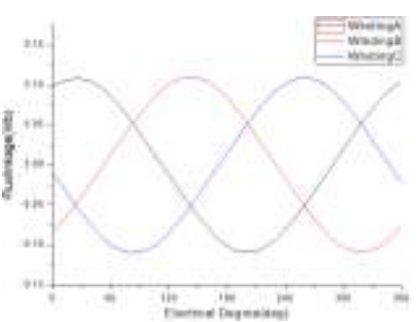

(c) Unilateral flat-plate LSM

Fig. 3. Flux linkage of the four LSMs under no-load condition. (a) and (b) are the flux linkage of LSM A and LSM B shown in the Fig. 1. (c) and (d) are the flux linkage of LSM C and LSM D shown in the Fig. 2.

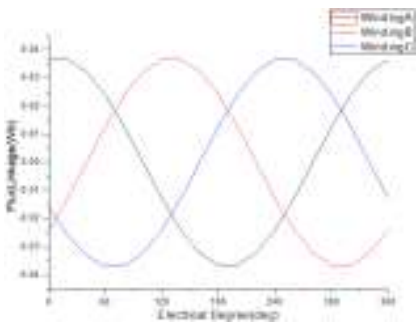

(b) Bilateral flat-plate LSM

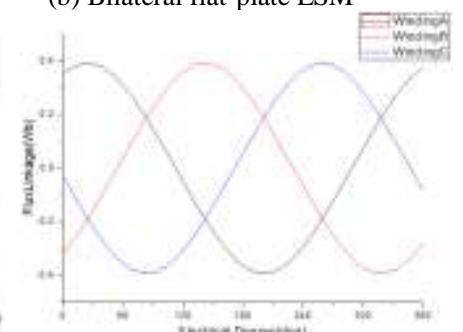

(d) Bilateral flat-plate LSM (a) LSM A

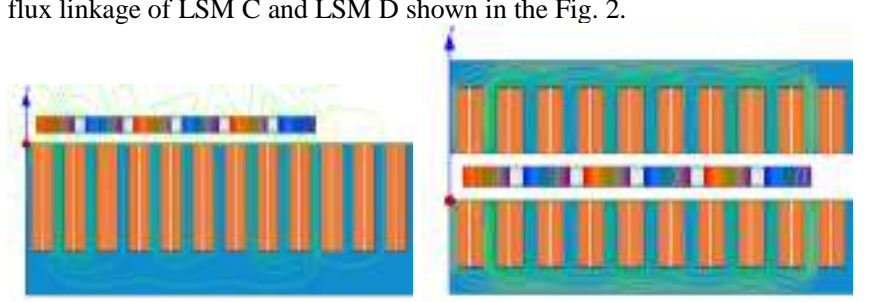

(b) LSM B
Fig. 4. Flux distribution of LSM A and LSM B shown in the Fig. 1.

\section{MAGNeTIC PARAMETER COMPARISON}

In this section, by using FEM the main magnetic parameters of LSM with four different configurations have been obtained. Fig. 3 shows the flux linkage of these LSMs, it can be seen that all LSMs can have three phase symmetrical magnetic flux distribution. The magnitude of the magnetic flux for machine $\mathrm{A}, \mathrm{B}, \mathrm{C}$ and $\mathrm{D}$ is $0.0175 \mathrm{~Wb}, 0.0365 \mathrm{~Wb}, 0.12 \mathrm{~Wb}$ and $0.4 \mathrm{~Wb}$ respectively. As shown, the flux linkage of LSM can be improved by using bilateral side primary stator configuration as the flux leakage is decreased. The magnetic flux distribution of the LSM A and LSM B is illustrated in Fig. 4. The bilateral side primary stator can bring LSM with the advantage of symmetrical magnetic pull force as well. With using distributed winding, the magnetic flux across the winding will be improved if compared with that with concentrated winding configuration. The main reason is that the length of HTS bulks is longer and thus more magnetic flux can be produced. However, the application of distributed winding will bring the machine with longer end length of the winding and thus the cop- 
per loss will be increased. Therefore, from the viewpoint of magnetic flux the flux linkage of LSM D is the highest one.

Induced voltage is another important parameter to represent the performance of electrical machine, it is obtained by using below equations,

$$
\begin{gathered}
=N \\
e=\frac{d}{d t}
\end{gathered}
$$

where $\Psi$ is the flux linkage, $N$ the turn number, $\varphi$ the magnetic flux, and $e$ the induced voltage. Fig. 5 shows the induced voltage of these LSMs respectively. As the induced voltage is obtained based on the deviation of magnetic flux linkage, the magnitude of the induced voltage of LSM D is the highest one among these machines.
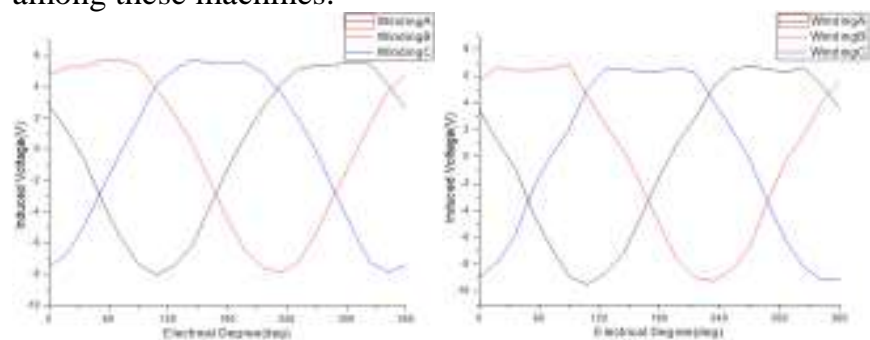

(a) Unilateral flat-plate LSM

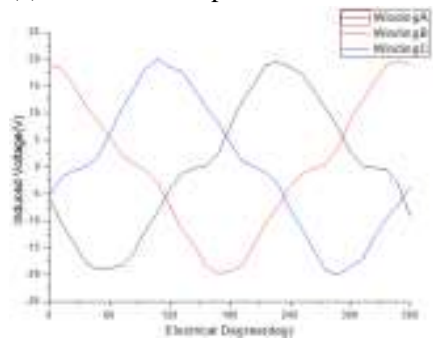

(b) Bilateral flat-plate LSM

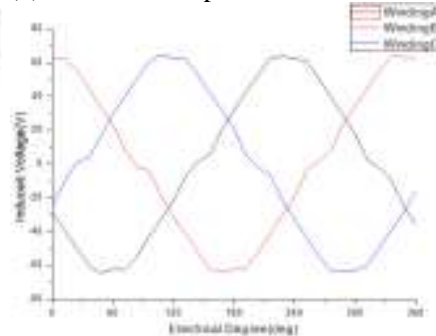

(c) Unilateral flat-plate LSM

(d) Bilateral flat-plate LSM

Fig. 5. Induced voltage of the four LSMs under no-load condition. (a) and (b) are the induced voltage of LSM A and LSM B (c) and (d) are induced voltage of the LSM C and LSM D

For LSM, the thrust force is most important parameter. In this paper the electromagnetic force along $\mathrm{x}$-direction is the thrust force. By using FEM, the force along $\mathrm{x}$-direction of these LSMs at the current density of $2.55 \mathrm{~A} / \mathrm{mm}^{2}$ is illustrated in Fig. 6. The aim of linear machine design is to achieve highest average thrust force and lowest thrust force ripple. It can be seen that the rated thrust force of LSM A is about $620 \mathrm{~N}$ while that of LSM B is about $809 \mathrm{~N}$. As shown the average force for LSM C and LSM D is $920 \mathrm{~N}$ and $1700 \mathrm{~N}$ respectively. The calculated force of these LSMs have the same relationship with the calculated induced voltage. The utilization of the distributed winding and bilateral topology will bring the LSM with better performance.

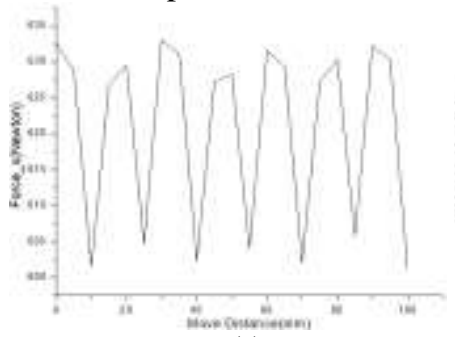

(a)

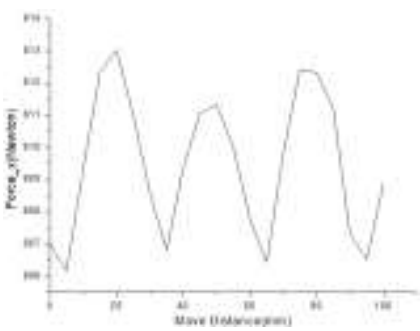

(b)

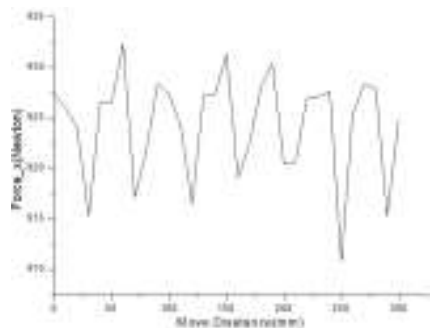

(c)

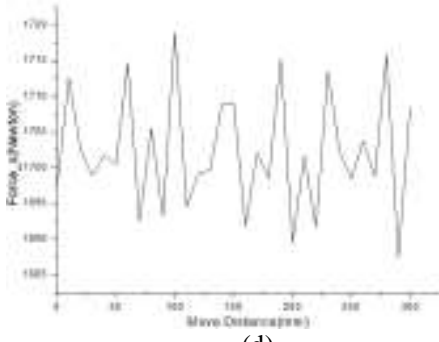

(d)
Fig. 6. Force $x$ of the four LSMs under load condition. (a) and (b) are the Force_x of LSM A and LSM B (c) and (d) are Force_x of the LSM C and LSM D

Table II tabulates the comparison of peak-to-peak and average thrust force of these four LSMs. It can be seen that the force ripple of LSM A is the highest one. LSM C had the lowest force ripple, reaching $0.77 \%$. Compared with other LSMs, LSM D has the maximum thrust force, and the thrust force ripple is lower than that of LSM A and LSM B. Therefore, it can be regarded as the best configuration for the LSM.

TABLE II FORCE AND FORCE RIPPLE COMPARISON OF THESE LSMS

\begin{tabular}{ccccc}
\hline \hline \multirow{2}{*}{ Item } & \multicolumn{2}{c}{ single } & \multicolumn{2}{c}{ double } \\
& concentrated & distributed & concentrated & distributed \\
\hline Avg/N & 620.92 & 924.33 & 809.46 & 1702.23 \\
P-P/N & 30.72 & 15.20 & 6.22 & 24.41 \\
Force ripple & $4.94 \%$ & $1.64 \%$ & $0.77 \%$ & $1.43 \%$ \\
\hline
\end{tabular}

The unbalanced magnetic pull force between the primary stator and the secondary mover will bring LSM with a great of drawbacks, thus it cannot be ignored in the analysis of the LSM with above four configurations. The calculated unbalanced magnetic pull force of these four LSMs are illustrated in Fig. 7. As shown, for bilateral side primary stator and one secondary mover configurations the average unbalanced magnetic pull force equals 0 , thus it can be good for some applications. However, for the magnetic levitation applications, this kind force can be useful. For the effect of the different winding configurations, the distributed winding will bring the LSM with lower unbalanced magnetic force.

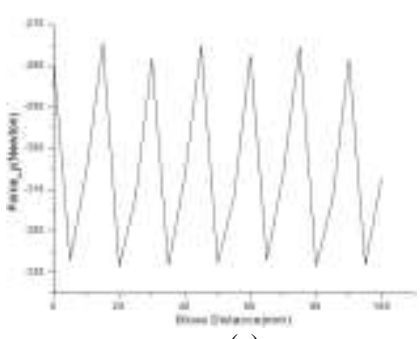

(a)

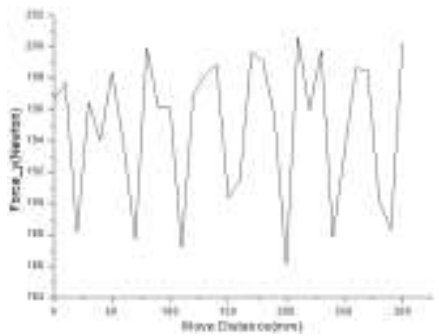

(c)

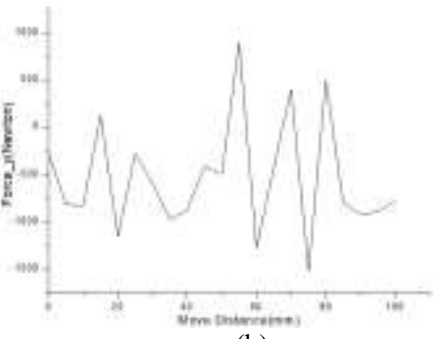

(b)

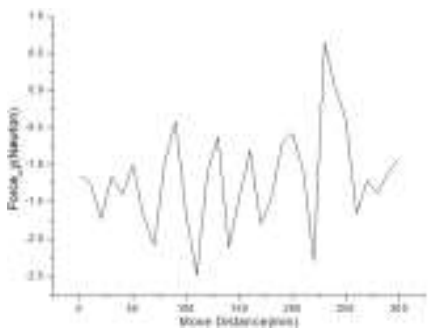

(d)
Fig. 7. Force_y of the four LSMs under load condition. (a) and (b) are the Force_y of LSM A and LSM B, (c) and (d) are Force_y of the LSM C and LSM D. 
The core loss produced in LSM will reduce the efficiency of the LSM, thus it has been analyzed. Fig. 8 shows the calculated core loss of these four LSMs at the current density of 2.55 $\mathrm{A} / \mathrm{mm}^{2}$ and the speed of $0.45 \mathrm{~m} / \mathrm{s}$. As shown the core loss of LSM A is about $13 \mathrm{~W}$, that of LSM B is about $3.5 \mathrm{~W}$, that of LSM C is about $5.5 \mathrm{~W}$ and that of LSM D is about $5.7 \mathrm{~W}$. It can be seen that for the concentrated winding configuration, the adoption of two primary stators will make the LSM with much lower core loss. As for the distributed winding configuration, the difference resulted by one primary stator or two primary stators is very small. (a)

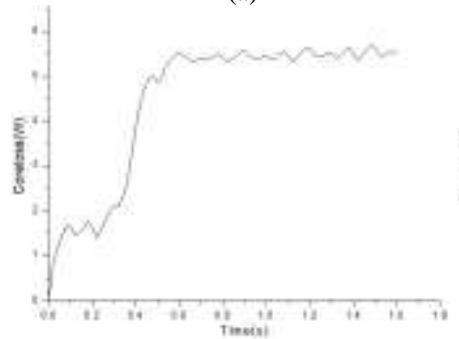

(c)

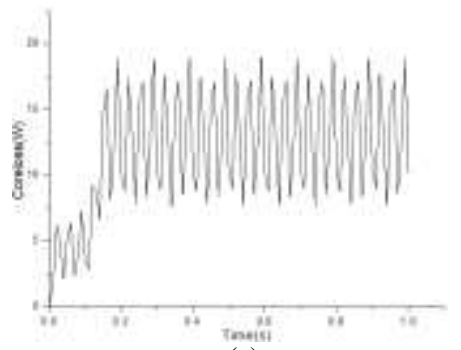

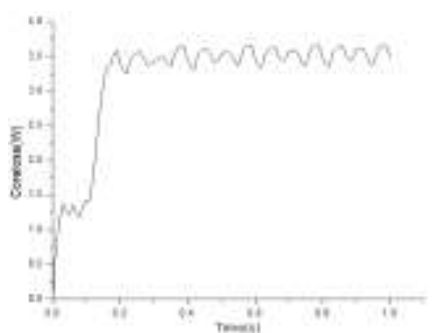

(b)

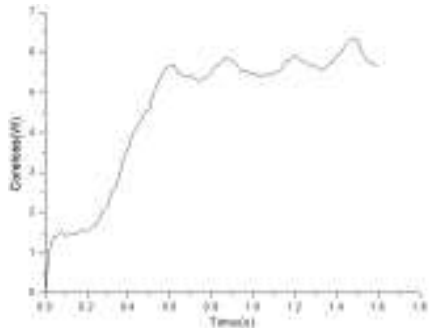

(d)
Fig. 8 Core loss of the four machines under load condition. (a) and (b) are the core loss of LSM A and LSM B, (c) and (d) are the core loss of LSM C and LSM D.

\section{CONCLUSIONS}

In this paper, LSM with different stators and winding configurations are analyzed and compared. Specifically, LSM A with one primary stator, one secondary mover and concentrated winding, LSM B with two primary stators, one secondary mover and concentrated winding, LSM C with one primary stator, one secondary mover and distributed winding, LSM D with two primary stators, one secondary mover and distributed winding. With the help of FEM package MAXWELL 2D, the main parameters and performance of these LSMs has been analyzed and compared. It can be seen that with two primary stator configurations the average magnetic thrust force of the LSM can be improved and also with the adoption of distributed winding the force can be increased. As for unbalanced magnetic force, it can be known that the two primary stators will bring the LSM with lower force, it is interested in many applications. However, for some determined applications e.g. the magnetic levitation application the unbalanced magnetic force is welcome. As for the core loss comparison, it can be seen that for the LSM with distributed winding, the effect resulted by the stator configurations is quite low.

\section{REFERENCES}

[1] Wenxiang Zhao, Ming Cheng, , Jinghua Ji, Ruiwu Cao, Yi Du, and Fuhua Li,"Design and Analysis of a New Fault-Tolerant Linear Permanent-Magnet Motor for Maglev Transportation Applications," IEEE Transactions On Applied Superconductivity, Vol. 22, No. 3, June 2012.

[2] J. Chang, D. Kang, J. Lee, and J. Hong, "Development of transverse flux linear motor with permanent-magnet excitation for direct drive applications," IEEE Trans. Magn, Vol. 41, No. 5, pp. 1936-1939, May 2005 .

[3] Q. Wang, J. Hu, J. Zhang, C. Liu, Y. Li, J. Zou, and H. Zhao,"Design considerstion of tubular transverse flux linear machines for electromagnetic launch application," IEEE Tran. Plasma Sci,Vol.43,No.5,pp.1248-1253, May.2015

[4] L. Li, D. Pan, and X. Huang, "Analysis and optimization of ironless permanent-magnet linear motor for improving thrust," IEEE Trans. Plasma Sci., vol. 41, no. 5, pp. 1188-1192, May 2013.

[5] J. Duan, H. Zhou, and N. Guo, "Electromagnetic design of a novel linear maglev transportation platform with finite-element analysis," IEEE Trans. Magn, Vol. 47, No. 1, pp. 260-263, Jan. 2011.

[6] Z. Q. Zhu, Ahlam L Shuraiji, and Q. F. Lu, "Comparative Study of Novel Tubular Partitioned Stator Permanent Magnet Machines," IEEE Trans. Magn, Vol. 52, No. 1, Jan. 2016.

[7] A. Y. M. Abbas and J. E. Fletcher, "Efficiency evaluation of linear permanent magnet synchronous machines using the synthetic loading method," in Proc. Power Electron. Specialists Conf. (PESC), Jun. 2008, pp. 3074-3080

[8] J. X. Jin, L. H. Zheng, Y. G. G, and J. G. Zhu, "Development of high temperature superconducting machines," Journal of Japan Society of Applied Electromagnetics and Mechanics, Vol. 15(s), pp. S88-S91, 2007.

[9] Luhai Zheng, Jianxun Jin, Yuoguang Guo, Wei Xu , and Jianguo Zhu, "Performance Analysis of an HTS Magnetic Suspension and Propulsion System With a Double-Sided HTS Linear Synchronous Motor,"IEEE Transaction On Magnetics, Vol. 48, No. 2, February 2012.

[10] Jianxun Jin, Lu Hai Zheng, You Guang Guo, Jian Guo Zhu, Colin Grantham, Charles Christopher Sorrell, and Wei Xu, "High-Temperature Superconducting Linear Synchronous Motors Integrated With HTS Magnetic Levitation Components," IEEE Transactions On Applied Superconductivity, Vol. 22, No. 5, October 2012.

[11] E. Masada, "Linear drives for industrial applications in Japan-History, existing state and future prospect," in Proc. LDIA'95, 1995, pp. 9-12.

[12] J. Wang, W. Wang, and K. Atallah, "A linear permanent-magnet motor for active vehicle suspension," IEEE Trans. Veh. Technol, Vol. 60, No. 1, pp. 55-63, Jan. 2011.

[13] L. Yan, "Recent progress of superconducting magnet technology in China," IEEE Transactions. Applied. Superconductivity, Vol. 20, No. 3, pp. 123-134, Jun. 2010.

[14] I. Sakai and T. Higuchi, "Dynamic properties of magnetic levitation system using high-temperature superconductors," IEEE Transaction Applied Superconductivity, Vol. 21, No. 3, pp. 1515-1518, Jun. 2011.

[15] Mao Yuan, Shuangxia Niu, "Design and Analysis of a Novel Modular Linear Double-Stator Biased Flux Machine," IEEE Transaction On Magnetics, Vol. PP, No. 99, June 2018.

[16] J. Bao, B.L.J Gysen, E.A.Lomonova, "Hybrid Analytical Modeling of Saturated Linear and Rotary Electrical Machines: Integration of Fourier Modeling and Magnetic Equivalent Circuits," IEEE Transaction On Magnetics, Vol. PP, No. 99, June 2018.

[17] Zhi H. Wu and Jian X. Jin, "Novel Concept of Dish Stirling Solar Power Generation Designed With a HTS Linear Generator," IEEE Transaction Applied Superconductivity, Vol. 24, No. 5, pp. 1515-1518, Oct. 2014.

[18] Jian Xun Jin, Lu Hai Zheng, You Guang Guo, Jian Guo Zhu, Colin Grantham, Charles Christopher Sorrell, and Wei Xu, "High-Temperature Superconducting Linear Synchronous Motors Integrated With HTS Magnetic Levitation Components," IEEE Transaction Applied Superconductivity, Vol. 22, No. 5, pp. 1515-1518, Oct. 2012. 